\title{
Forum
}

\section{Reply to Raoul du Toit}

\author{
Sky K. Alibhai and Zoë C. Jewell
}

In 1996 we estimated the cost of fitting one rhino with a radio-collar at Sinamatella to be US $\$ 1500$ (Alibhai et al., 1996). The salary of one game-scout (and thus the support of his family) was then less than half of this figure. Nevertheless du Toit (this issue) states that radio-collaring is generally undertaken where manpower is insufficient. Zimbabwe has high unemployment and abundant manpower, which illustrates the need to readdress the use of financial resources in rhino monitoring.

$\mathrm{du}$ Toit contends that radio-collaring makes monitoring more efficient and economical, and refers to trials (du Toit, 1996). Unfortunately he does not present data to support his view, and there has been no published assessment of the cost-effectiveness of radio-collaring or improved performance through research and development. At Sinamatella (Alibhai \& Jewell, this issue) we believe that no serious attempt was made to improve on very poor success rates, because the same strap collar design and fitting technique was used in four successive radio-collaring operations with equally high failure rates. We do not have space here to comment on du Toit's remarks concerning the use of alternative technologies for rhino monitoring, but would be happy to correspond directly with interested parties on this matter.

du Toit justifies the use of radio-collaring for routine monitoring by arguing that Zimbabwe is an exceptional case compared with other range states. However, there are several large conservation areas in other range states that have low rhino densities, e.g. Selous Game Reserve in Tanzania and Masai Mara National Park in Kenya, but which do not use routine radio-collaring for monitoring. In a recent personal communication, $K$. Adcock of the African Rhino Specialist Group stated:

'I think that Zimbabwe is the only place where repeated radio collaring is used...for security [and] in the majority of other cases it is not used in the same manner although [other countries] should be warned against potentially adopting the same approach as Zimbabwe. ...radio-tracking is in practice only used in introduction circumstances or [in the majority of cases] for scientific research purposes.

We agree that new technology should be used wherever it is of benefit in monitoring, but believe it should be non-

Sky K. Alibhai (Corresponding author) and Zoë C. Jewell Rhinowatch, Sinamatella Camp, P. Bag 5941, Hwange, Zimbabwe. Present address: Apartado 210, 8550-909 Monchique, Portugal

E-mail: rhinowatch@clix.pt

Manuscript accepted for publication 18 June 2001 invasive, in order to minimize disturbance to natural behaviour and physiological processes (Jewell et al., 2001). This is illustrated in the points we raise (this issue) relating to rhino anatomy and behaviour.

Regarding welfare, the lesions in our Figs 3 and 4 were only detected 4 months after the animal had been collared. Our data (this issue) show that 15 per cent of the rhinos at Sinamatella sustained collar injuries. A further 13 per cent of strap collars were never recovered, and it is thus likely that some of these produced similar lesions. Surely these are objective data and sufficient cause for welfare concern?

We have provided strong evidence linking immobilization with a reduction in fertility of female black rhino at Sinamatella (Alibhai et al., 2001). The relatively high estimate for the population growth rate at Sinamatella quoted by du Toit included those years when no immobilization was undertaken (and when population growth rates were higher), and of course not all females were immobilized in each year. The pitfalls of accurately assessing population growth rates of black rhino over only a few years are well known (Owen-Smith, 1992). However, when we analysed the performance of individual females (Alibhai et al., 2001) the link between fertility and immobilization became clear.

Despite du Toit's argument that radio-collaring of rhinos for routine monitoring can be made cost-effective, we feel that all evidence indicates otherwise. We believe that continued use of substantial resources for this purpose detracts from progress along more productive routes to effective rhino conservation.

\section{References}

Alibhai, S.K., Jewell, Z.C. \& Towindo, S.S. (1996) The Density, Distribution and Ranging of the Black Rhino (Diceros bicornis) in the Sinamatella Intensive Protection Zone, Hwange National Park, Zimbabwe. Report to the Department of National Parks and Wild Life Management of Zimbabwe.

Alibhai, S.K., Jewell, Z.C. \& Towindo, S.S. (2001) The effects of immobilization on fertility in female black rhino (Diceros bicornis). Journal of Zoology, 253, 333-345.

Jewell, Z.C., Alibhai, S.K. \& Law, P.R. (2001) Censusing and monitoring black rhino (Diceros bicornis) using an objective spoor (footprint) identification technique. Journal of Zoology, 254, 1-16.

Owen-Smith, R.N. (1992) Megaherbivores. Cambridge University Press, Cambridge, UK.

du Toit, R.F. (1996) Modern technology for rhino management. Pachyderm, 22, 18-24. 